\title{
Marine Environmental Protection: A Highly Efficient Method of Degradation of Heavy Oil Pollution on Coastal Beaches \\ MC Lin
}

Department of Maritime Police, Central Police University, Taiwan

*Corresponding author: Lin MC, Department of Maritime Police, Central Police University, Taiwan, Tel: 886-027360411; E-mail: chuck321@ms73.hinet.net

Rec date: Mar 21, 2016; Acc date: Mar 29, 2016; Pub date: Mar 31, 2016

Copyright: @ 2016 Lin MC. This is an open-access article distributed under the terms of the Creative Commons Attribution License, which permits unrestricted use, distribution, and reproduction in any medium, provided the original author and source are credited.

\begin{abstract}
Coastal oil pollution, especially occurring on coastal beach, is thorny issue when it comes to environmental restoration. Today, bioremediation is the current method used in treating beach oil pollution. Although it has undergone some improvements, this method still doesn't work very well.

In this paper, a highly efficient procedure in bioremediation is studied. This method, using more varieties of microbes and water recirculation, may degrade heavy oil in a few days. Three sets are designed into this study. The method in Set 1 is a traditional degradation using a single microbe with only fertilizers and dispersant. The method in Set 2 is a highly efficient degradation process with more varieties of microbes, fertilizers, dispersant, fresh water recirculation and pumped-in air supplying. Set 3 is s control set which degrades heavy oil with the original microbe in beach sand only. Results of these experiments show that the process used in Set 2 will completely degrade heavy oil within 60 days. This is more efficient than by the traditional method as in Set 1, which takes more than 200 days.
\end{abstract}

Keywords: Oil pollution; Bioremediation; Fresh water recirculation; Air supply

\section{Introduction}

Oil spills occurred all over the world. Visible spills may occur in marine areas, rivers or land. Invisible spills also may occur from industrial waste water, exhaust from daily living, even from some manufacturers stealthily pouring their dregs into the sewer system in the name of "pollution prevention". Oil pollution occurs at all times and places. Man's morals do not match his technological capabilities.

Surveying marine pollution, a prodigious number of oil spills may be due to release of effluents from offshore platforms, drilling rigs and wells, as well as spills of crude oil from tankers. Aside from the famous Deep water Horizon oil spill in the Gulf of Mexico recently, great amounts of oil are released into the environment from marine accidents, such as ship collisions, groundings or mechanical failures.

The environment is highly vulnerable to oil spill disasters, and people pay a high price to repair the wounds. In March 1989, the oil tanker 'Exxon Valdez' spilled 260,000 barrels of crude oil in Prince William Sound, Alaska [1]. It was estimated that the oil pollution killed from 100,000 to 300,000 birds. In September 2002, the oil tanker "Prestige" sunk off the Galician coast, causing one of the most infamous oil spills in history by affecting the entire coastline, particularly the exposed rocky shores and beaches [2]. Devastation and debris met the eye everywhere.

Because the ability of Nature to degrade oil is quite weak under such frequent incidents of oil pollution, we must find effective methods for treating oil pollution [3]. In times past, they treated oil pollution by oil bloom, absorbent sheets or oil skimmers. When marine accidents occurred, the polluting oil would be isolated by an oil boom as soon as possible to prevent the oil from diffusing into the sea. Then absorbent sheets or oil skimmers were used to play their roles. But the oil was not always sequestered so well. Some landed on beaches by tides, and some landed on coastal rock. Such equipment was hard to use in treating sandy beach and rocky coast. Today, bioremediation is a useful method in treating beach oil pollution as many researchers have verified.

Recently, microbial degradation for diesel oil and heavy oil has developed to the point where affected areas have actually become tourist attractions [4-6]. Although this was great news in the field of oil pollution remediation, the efficiency in degradation was mostly not quite satisfactory because the results were not optimal. Although people did learn that the efficiency in degradation could be improved by adding fertilizers and oxygen, maintaining temperature and pressure [7], and using dispersant, there are still two problems that exist in bioremediation: (1) Most researchers have investigated bioremediations only for fresh water environments. But, once in a sea water environment, the efficiency of bioremediation will be canceled because of high salinity (2). In experimental systems, in which the water used is full of microbes, dispersants are used to disperse oil so that microbes can easily degrade the oil. But in a marine environment, people have no other option than to use only dispersants to disperse continuous oil spilling from an oil field or oil platform. It is unknown whether microbes stay around the dispersants or not due to the vast expanse of ocean. It is well known, however, that the combinations of oil and dispersant follow the tides and ride the waves, sink down into the sea, get ingested by fish, kill corals or poison farming areas. The result is dire consequences. In a word, it appears that the studies about dispersants on degradation of oil-based pollutants are nonsense. Consequently, one must solve these problems to improve bioremediation [8].

This article details an investigation into a highly efficient procedure for bioremediation. This procedure utilizes a group of microbes that are oil bacteria cultured by synergy and bio-augmentation to satisfy hot surroundings, involving water recirculation and supplying oxygen 
Page 2 of 3

to improve metabolism and thus increase degradation efficiency, as shown in Figure 1:

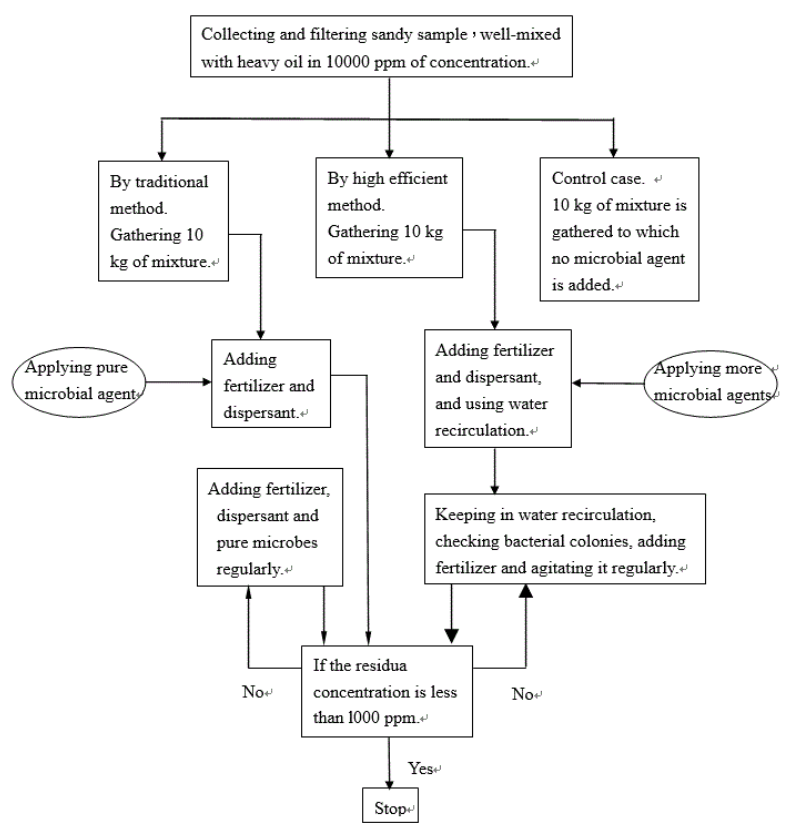

Figure 1: The flowchart of degradation.

\section{Materials and Methods}

The experimental details are summarized below:

A significant sample of beach sand was collected from Tainan beach in Taiwan $(22.960187,120.177629)$, which is at high risk for oil pollution, in order ensure that the results of the experiment approximate real conditions.

The sample was thoroughly mixed with heavy oil to $10,000 \mathrm{ppm}$ of concentration. Three cases of samples were analyzed, as shown as in Figure 1. In Set $1,10 \mathrm{~kg}$ of 10,000 ppm mixture is gathered, to which pure microbial agent is applied so as to serve as an experimental case by the traditional method. In Set $2,10 \mathrm{~kg}$ of mixture is gathered, to which more microbial agents are applied along with water recirculation, to serve as an experimental case by the highly efficient method. In Set 3,10 kg of mixture is gathered, to which no microbial agent is added, as a control case.

Because heavy oil is a gelatinous substance with high viscosity, it is difficult to create a uniform mixture. One must add solvent to the heavy oil in order to transform it onto a liquid state, and then pour it into sand. Though heavy oil is thoroughly mixed in, the solvent itself will volatize completely.

Water recirculation and air supply were designed into Set 2 . The circulating water, forced by pump and flowing by gravitation, brings fresh air to microbes to promote their metabolism. Additionally, the soil was stirred and mixed with fertilizers.

These experimental sets (Set 1 and Set 2 ) were placed in sunlight in high temperature surroundings to improve their living environment and maintain higher efficiency during degradation.

\section{Experimental equipment}

The equipment and consumables includes steel ponds, microbial agent, air feeder, water feeder, water recirculation system, thermometer, dry oven, autoclaves sterilizers, cross-beam agitator, double-Shot Py-GC system, microbalance, magnetic stirrer, clean bench sand, pure water, inorganic nitrogen, and phosphorus.

\section{Results and Discussion}

The experimental procedure and details are designed with 3 sets and shown in Figure 1. Set 1 and 2 are experimental sets whereas Set 3 was the control set. The method used in Set 1 is a traditional study in which fertilizers, dispersant and pure microbes are regularly added. In Set 2, not only fertilizers and dispersant were used, but also fresh water recirculation and a forced air supply. Also in Set 2, more varieties of microbes, cultivated from oil microbes adapted to high temperature surroundings, were used only at the initial stage. Although these microbes were added only initially, the soil still maintained high bacterial colonies through normal metabolism. Both Set 1 and 2 were regularly checked to see whether the oil concentration became less than 1,000 ppm-the value considered to be unpolluted according to Environment Protection Administration standards. Set 3 is a control set which was moistened and contained only the original microbes for degradation without fertilizers and dispersant.

The residual concentration of heavy oil during the degrading process is shown in Figure 2. This figure indicates that the concentration curve in Set 1, using the traditional method of a single type of bacteria, degraded the heavy oil to less than 1,000 ppm over more than 200 days. In most cases, this method can give a stable result but the degradation occurs at a crawl. On the other hand, there's been a measureable improvement in Set 2. In Set 2, the residual concentration of heavy oil was decreased to less than $1,000 \mathrm{ppm}$ in only 90 days. The operation in Set 2 is an improved method using more varieties of oily microbes and forcing water recirculation, which sharply reduces oil concentration. All actions were aimed at creating a comfortable environment for the bacteria so as to improve their effectiveness. Consequently, there was a rapid drop in residual heavy oil concentration. However in Set 3, degraded only by the original bacteria, a good result was not achieved.

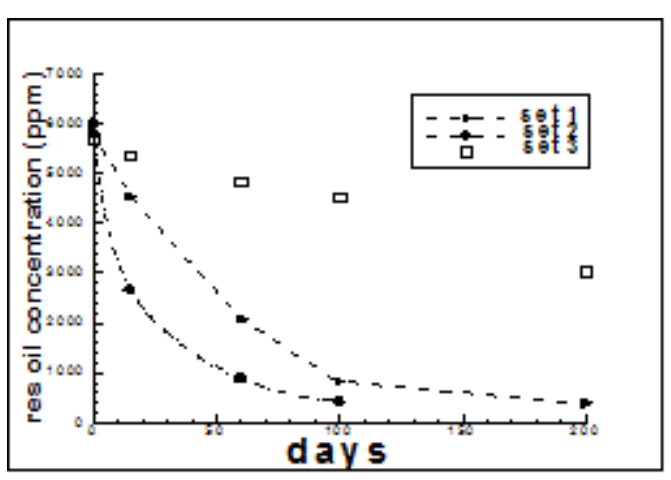

Figure 2: Residual concentration of heavy oil.

The experimental data of bacterial colonies during degradation are presented in Figure 3. The bacterial colonies in Set 2 maintained a high value 10 times that of Set 1, enabling the degradation period in Set 2 to be reduced from more than 200 days down to only 90 days. This 
finding is of great practical importance in that the inclusion of water recirculation and air supply into the design led to maintaining higher degradation ability than using only the traditional method as in Set 1. But bacterial colonies in Set 3 remain low value for four orders. In other words, the bacterial colonies in Set 3 were only one ten thousandth of that in Set 2, which showed poor degradation.

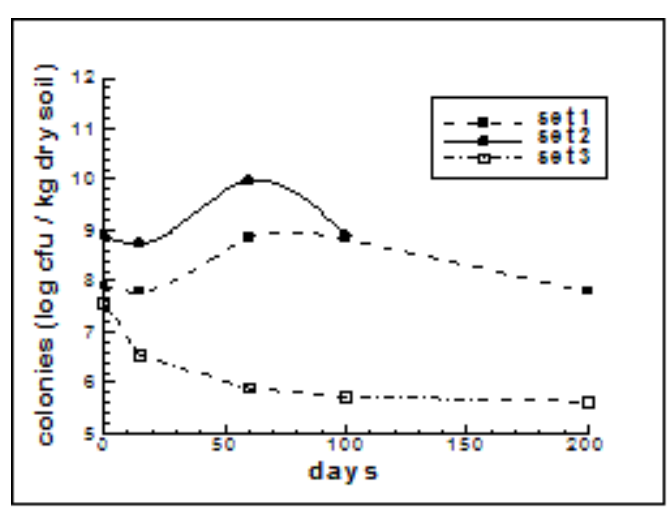

Figure 3: Bacterial colonies.

Figure 4 denotes the variation of $\mathrm{pH}$ in the samples. Apparently, the $\mathrm{pH}$ in Set 2 was always smaller than in Set 1 . The reason for the variation is due to the metabolic derivatives form acid during degradation. This is because the negative slope $\mathrm{pH}$ curve signifies the rate of degradation. A sharper decay of $\mathrm{pH}$ implies a better degradation result. The difference of $\mathrm{pH}$ between Set 2 and Set 1 gradually rises to the maximum value at 60 days. The $\mathrm{pH}$ of Set 2 as well as Set 1 remains constant after 90 days as the degrading ability of microbes becomes poor because of little heavy oil, even though their degradation is still continuous. Similarly, the $\mathrm{pH}$ in Set 3 remains constant after 60 days for stagnant degradation.

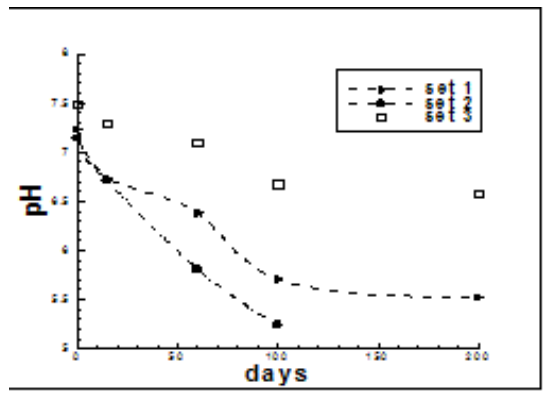

Figure 4: $\mathrm{pH}$ variation.

As previously stated, the degradation using a group of microbes appears more powerful than by using single type of microbe. Heavy oil, as we know, is ultimately composed of complex hydrocarbons. Each kind of microbe prefers its hydrocarbon. Consequently, degradation efficiency is lower when single microbial degradation is employed. However, the degrading efficiency is successfully raised by complementary or competing group bacteria, as shown in Figure 2.

The inclusion into the design of water recirculation and air supply aims to establish appropriate conditions for bacterial growth and breeding. The more appropriate the conditions for bacterial breeding, the greater the bacterial colonies, and thus the higher efficiency in degradation. Of course, inclusion of water recirculation and air supply is not the only way to establish appropriate conditions for bacterial, which should always be done on a case by case.

\section{Conclusion}

An efficient method of degradation of heavy oil pollution has been investigated. From the present results obtained, one can draw the important conclusions:

Degradation by multiple bacteria is an efficient method of remediating coastal pollution. A design that includes water and air supply is important for bacteria metabolism in order to maintain high bacterial colonies.

Degradation of beach oil pollution also has been developed. This method can be applied to beach oil pollution directly. Note that this study has examined mixed oil and sand only in the laboratory. A further study will be done on actual coastal pollution in situ.

\section{References}

1. John FP, Lensink CJ, Butler W, Kendziorek M, Nysewander D (1990) Immediate impact of 'Exxon Valdez' oil spill on marine birds. American Ornithologists Union 107: 387-397.

2. Lastra M, Junoy J, Castellanos C, Viéitez JM (2005) Biological impacts of oil pollution and cleaning in the intertidal zone of exposed sandy beaches: Preliminary study of the "Prestige" oil spill". Estuarine, Coastal and Shelf Science 65: 19-29.

3. Lin MC, Kao JC (2014) A New method for treating Coastal Oil Pollution. International Journal of Environmental Pollution and Remediation, Proceedings of the 4th International Conference on Environmental Pollution and Remediation Prague, Czech Republic, p: 80.

4. Margesin R, Schinner F (1997) Bioremediation of diesel-oil-contaminated alpine soils at low temperatures. Applied Microbiology and Biotechnology 47: 462-468.

5. Lin MC (2011) The advanced development of microbial degradation to oil pollution. The conference of salvage at sea. pp: 97-106.

6. Tsutsumi H, Kono M (2000) Bioremediation on the shore after an oil spill from the Nakhodka in the Sea of Japan. I. Chemistry and characteristics of heavy oil loaded on the Nakhodka and biodegradation tests by a bioremediation agent with microbiological cultures in the laboratory. Marine Pollution Bulletin 40: 308-314.

7. Kao JC, Lin MC (2015) An advanced treatment on coastal oil pollution. Global Advanced Research Journal of Management and Business Studies 4: 259-266.

8. Lin MC (2011) The study of remediation on coastal pollution, the 17th symposium of maritime police. pp: 115-125. 